\title{
UM RELANCE SOBRE A TRAJETÓRIA DE CLARA MAFRA
}

\author{
Claudia Wolff Swatowiski ${ }^{1}$
}

Recebido em: Setembro 2014

Aceito em: Dezembro 2014

Para citar este artigo:

SWATOWISKI, Claudia. "Um relance sobre a trajetória de Clara Mafra". In: Revista Intratextos, 2014, vol, no, p. 129-134. DOI: http://dx.doi.org/10.12957/intratextos.2014.15808.

1 Claudia Wolff Swatowiski é pós-doutoranda no Programa de Pós-Graduação em Ciências Sociais da UERJ. Teve Clara Mafra como orientadora de mestrado e doutorado. Seu projeto de pós-doutorado estava em andamento sob a supervisão de Mafra quando ela lamentavelmente faleceu. 
Em julho de 2013, a antropóloga Clara Cristina Jost Mafra faleceu precocemente, interrompendo uma trajetória acadêmica bastante intensa, dinâmica e criativa. Então professora associada do Programa de Pós-Graduação em Ciências Sociais da Universidade do Estado do Rio de Janeiro, Clara Mafra deixou uma contribuição muito significativa para os estudos das religiões em meio urbano, mais especificamente do pentecostalismo, no Brasil e em contextos transnacionais. Neste breve escrito, retomamos sua trajetória acadêmica como forma de homenagear uma profissional extremamente dedicada e comprometida com a produção intelectual e com o ensino das Ciências Sociais. Para tanto, valho-me não apenas daquilo que Clara deixou escrito, mas também da memória de ricos diálogos acadêmicos e valiosas conversas informais que tivemos.

Gaúcha nascida em Ijuí, Clara Mafra mudou-se para Campinas em 1983 para cursar Licenciatura em Ciências Sociais na Unicamp. Como trabalho de conclusão de curso, apresentou a monografia intitulada "Coletivo Feminista de Campinas - um estudo de caso" (Mafra, 1987), orientada pela professora Suely Kofes. Em seguida, Mafra iniciou o mestrado, também na Unicamp, tendo defendido, em 1993, a dissertação "Autoridade e Preconceito - estudos de caso sobre grupos ocupacionais em Campinas", na qual se dispôs a participar do debate sobre o "enigma da classe média" a partir de uma aproximação da visão de mundo de diferentes grupos de profissionais.

Logo após concluir sua dissertação, Clara Mafra juntou-se a uma equipe de pesquisadores do ISER (Instituto de Estudos da Religião), sob a coordenação de Rubem Cesar Fernandes, para a realização de um survey entre evangélicos na região metropolitana do Rio de Janeiro. $\mathrm{O}$ artigo "Gênero e estilo eclesial entre os evangélicos" publicado na coletânea Novo Nascimento (Fernandes et al, 1998) é resultado deste período de reflexões e lança luz sobre o perfil dos frequentadores de diferentes denominações evangélicas, levando em consideração a questão de gênero.

Entre 1996 e 1999, Mafra realizou seu doutorado no Programa de Pós-Graduação em Antropologia Social do Museu Nacional (UFRJ). Inicialmente, desenvolveu pesquisa na favela Santa Marta, que resultou no artigo "Drogas e Símbolos - redes de solidariedade em contextos de violência” (Mafra, 1998), publicado no livro Um século de favela, sob a organização de Marcos Alvito. Neste estudo, a antropóloga desenvolve uma reflexão precursora sobre a relação entre diferentes instituições e atores sociais, igrejas e grupo de narcotráfico.

Para seu doutorado, Clara Mafra também realizou pesquisa sobre o processo de expansão internacional da igreja brasileira neopentecostal Universal do Reino de Deus em Portugal. Os 
investimentos de trabalho de campo no Brasil e em Portugal deram origem à tese Na Posse da Palavra - religião, conversão e liberdade pessoal em dois contextos nacionais, defendida em 1999 sob a orientação de Otávio Velho. Em 2001, a tese foi publicada pela Imprensa de Ciências Sociais, editora portuguesa, tornando-se uma referência para os estudos sociológicos e antropológicos sobre as religiões no contexto português.

No mesmo ano, 2001, foi lançado no Brasil, pela Jorge Zahar Editor, o livro de divulgação científica Os Evangélicos, onde Mafra apresenta um panorama geral da trajetória dos missionários evangélicos, suas instituições e suas congregações no país.

Entre 2001 e 2002, Clara Mafra realizou pesquisa de campo com evangélicos em Cacoal, Rondônia, o que rendeu novas reflexões elaboradas no capítulo "A sedução em tempo de abundância: análise das igrejas pentecostais como objetos de arte" do livro Circuitos infinitos, organizado por Otávio Velho (2003), e no artigo "Jesus Cristo Senhor e Salvador da Cidade Imaginário Crente e Utopia Política", publicado na revista Dados (2006). Ambos os escritos são posteriores ao período que Mafra esteve em Aberdeen, Escócia, para seu primeiro pós-doutorado, sob a supervisão de Tim Ingold, e já trazem marcas da apropriação do aporte teórico oferecido pelo antropólogo britânico.

Segundo a própria Clara, Tim Ingold ajudava-lhe a resolver algumas de suas inquietações, propondo uma antropologia com amplitude interdisciplinar de abordagem fenomenológica. No artigo "World Without Anthropology", que integra a coletânea Cultural Improvisation and Creativity (Hallam e Ingold, 2007), Mafra explicita algumas de suas interrogações e conduz o leitor a uma reflexão densa sobre os limites da antropologia como disciplina de conhecimento. Também em uma interlocução direta com Ingold, no texto intitulado "Como o espírito educa a atenção?" (Mafra, 2013), a antropóloga debruça-se sobre os processos de conhecimento do mundo a partir de uma perspectiva pentecostalizada.

Com o suporte teórico de Ingold, Mafra desenvolveu um percurso de investigação que não enxergava limites para a análise antropológica. $\mathrm{Na}$ arte e na arquitetura, encontrava novas possibilidades de reflexão, como já anunciava no texto anteriormente citado (Mafra, 2003), e voltaria a elaborar mais tarde. "A arquitetura oferece tanto a capacidade de incorporar como de divulgar ideias e significados das mais diversas tradições", escreveu Mafra no artigo "Casa dos homens, casa de Deus”, publicado na revista portuguesa Análise Social (Mafra, 2007a). Neste texto, a antropóloga recorre à arquitetura e a elementos de composição dos templos como evidência de ideias, crenças, desafios e tensões para pensar o processo histórico de desenvolvimento do 
pentecostalismo.

Clara Mafra também desenvolveu estudos nos quais o meio urbano aparece como dimensão relevante e fundamental para se pensar as atividades religiosas e suas dinâmicas na sociedade contemporânea. Nesse sentido, organizou com Ronaldo de Almeida o livro "Religiões e Cidades Rio de Janeiro e São Paulo" (2009), publicação que traz seu artigo "Distância territorial, desgaste cultural e conversão pentecostal". Neste, Mafra procura compreender o chamado "anel pentecostal" - a ocorrência, nas últimas décadas, de um padrão de distribuição desigual das religiões no tecido metropolitano, com as populações de menor poder aquisitivo e de adesão pentecostal ocupando as áreas periféricas.

Em outra pesquisa realizada em Del Castilho, bairro que abriga a Catedral Mundial da Fé, sede da Igreja Universal do Reino de Deus, localizado na Zona Norte do Rio de Janeiro, Mafra e eu (2009a, 2009b) elaboramos uma reflexão sobre os processos de mudança os padrões de sociabilidade urbana e sua relação com o modo de se habitar a cidade, a partir de uma perspectiva diacrônica. Chamamos a atenção para as transformações da paisagem e das atividades desenvolvidas no bairro na sua relação com as dinâmicas religiosas, com o crescimento da cidade e da "cultura do medo".

Posteriormente, Clara Mafra investiu em uma aproximação da antropologia linguística na sua interlocução com a antropologia cultural, no interior do que tem sido chamado de 'antropologia do cristianismo'. Entre 2009 e 2010, Mafra esteve na Universidade da California, San Diego, para seu segundo pós-doutorado, sob a supervisão de Joel Robbins. O diálogo com a 'ideologia semiótica' rendeu uma importante contribuição para o debate sobre a questão da memória e evangélicos no Brasil. No artigo, "Saintliness and Sincerity in the formation of Christian Person",2 (Mafra, 2011a), Mafra procura responder a questão da especificidade do 'pentecostalismo' no Brasil, uma vez que os missionários pentecostais, eles próprios, geralmente criados católicos, se converteram através do proselitismo de missionários também de origem católica. Mafra localiza alguns dos marcadores utilizados por estes 'tradutores' sobre uma tradição protestante e discute como o enquadramento católico causa impacto nos arranjos e acomodações das ideologias semióticas da 'santidade' e 'sinceridade' no interior da religiosidade pentecostal.

Em continuidade ao debate sobre memória entre evangélicos, Mafra deixou-nos ainda outro

$2 \mathrm{O}$ artigo originalmente publicado na revista Ethnos foi traduzido e publicado em português na última edição da Religião \& Sociedade (Mafra, 2014). 
importante artigo. Em "A 'arma da cultura' e os 'universalismos parciais", publicado na revista Mana (Mafra, 2011b), a antropóloga localiza pontos de contraste na forma como católicos, afrobrasileiros e evangélicos se relacionam com as políticas públicas de patrimônio e de cultura, sublinhando tensões que emergem na produção de reconhecimento e de legitimidade social.

Paralelamente aos investimentos de pesquisa no Brasil, Mafra continuou alimentando uma rede de interlocução no circuito lusófono através da participação em projetos internacionais como o “Atlântico Cristão" - coordenado por Ramon Sarró, então professor no Instituto de Ciências Sociais da Universidade de Lisboa -, no qual atuava como consultora. Quando adoeceu, Mafra encaminhava a conclusão do projeto de cooperação internacional "A Igreja Universal do Reino de Deus, a teologia da prosperidade e direitos humanos em Angola", coordenado por ela e financiado pelo CNPq. Os resultados de investimentos em trabalhos de campo realizados entre 2011 e 2012 para este projeto foram apresentados no seminário internacional " $O$ trabalho da imaginação na textura do presente", evento que reuniu na UERJ um grupo significativo de pesquisadores de universidades do Brasil, Portugal, Angola e Moçambique, em torno de etnografias realizadas nos dois últimos países. Na ocasião, Mafra apresentou uma reflexão importante sobre as características do projeto de construção do Estado secular em Angola.

Resultados parciais de reflexões sobre a inserção da IURD no circuito lusófono foram publicados no artigo intitualdo "Edir Macedo's Pastoral Project" (2013), escrito por Clara Mafra, Claudia Swatowiski e Camila Sampaio. Nele, argumentamos que o grande triunfo e originalidade de Edir Macedo repousam em sua habilidade de transformar a "nova teologia cristã", para além de suas tendências liberais, em um projeto teológico popular. Consideramos a IURD uma vasta rede de instituições transnacionais firmemente conectados, que serve como canal de circulação de sermões, pessoas, objetos rituais, e "tecnologias do eu".

Por fim, é importante destacar a contribuição de Clara Mafra para os debates sobre dados do censo relativos à declaração de filiação religiosa, especialmente os de 2001 e 2010, problematizando a metodologia de produção dos resultados e as interpretações frequentemente elaboradas sobre eles (Mafra, 2004, 2013, 2013).

Sem dúvida, as poucas linhas delineadas aqui não são capazes de traduzir a real dimensão e relevância do trabalho de Mafra para a antropologia. Seu texto sempre muito bem escrito, com uma textura própria de quem tece cuidadosamente as palavras para apresentar ideias refinadas, sua capacidade de surpreender e criar impacto, sua ousadia na busca por novos caminhos para compreensão dos processos da vida, tornaram Clara Mafra uma pesquisadora e antropóloga única 
que deixou sua marca no caminho da produção de conhecimento sobre o mundo.

\section{Referências bibliográficas:}

FERNANDES, Rubem et al. Novo Nascimento - os evangélicos em casa, na igreja e na política. Rio de Janeiro: Editora Mauad,1998.

INGOLD, Tim and HALLAN, Elizabeth. (Org.). Creativity and Cultural Improvisation. Oxford: Berg Publishers, 2007.

MAFRA, Clara Cristina Jost. Coletivo feminista de Campinas - um estudo de caso. Monografia de graduação e Ciências Sociais. Unicamp. 1987. Autoridade e Preconceito estudos de caso sobre grupos ocupacionais em Campinas. Dissertação de mestrado. Campinas: PPGAS/Unicamp, 1993. Drogas e Símbolos - redes de solidariedade em contextos de violência. In: Zaluar, Alba. e Alvito, Marcos (orgs). Um Século de Favela. Rio de Janeiro: Fundação Getúlio Vargas, 1998. Na posse da palavra. Religião, conversão e liberdade pessoal em dois contextos nacionais. Lisboa: Imprensa de Ciências Sociais, 2002a. Os Evangélicos. Rio de Janeiro: Jorge Zahar Editor, 2002. A sedução em tempo de abundância: análise das igrejas pentecostais como objetos de arte. In: Otávio Velho. (Org.). Circuitos infinitos, comparações e religiões no Brasil, Argentina, Portugal, França e Grã-Bretanha. São Paulo: Attar Editorial/CNPq/Pronex, 2003. Censo da Religião: um instrumento dispensável ou reciclável?. Religião \& Sociedade, v. 24, p. 152-159, 2004. Jesus Cristo Senhor e Salvador da Cidade - Imaginário Crente e Utopia Política. Dados (Rio de Janeiro), v. 49, p. 583-614, 2006. Casa de Deus, Casa dos Homens. Análise Social, v. 182, p. 145-161, 2007a. World Without Anthropology. In: INGOLD, Tim and HALLAN, Elizabeth. (Org.). Creativity and Cultural Improvisation. Oxford: Berg Publishers, 2007b. Distância territorial, desgaste cultural e conversão pentecostal. In: MAFRA, Clara e ALMEIDA, Ronaldo de. Religiões e Cidades - Rio de Janeiro e São Paulo. São Paulo. Editora Terceiro Nome. 2009. Saintliness and Sincerity in the formation of the Christian person. Ethnos, v. 76, p. 448-468, 2011 a. A "arma da cultura" e os "universalismos parciais". Mana, v. 17, p. 607-624, 2011 b. Como o Espírito Santo Educa a Atenção?. In: Carlos Alberto Steil e Isabel Cristina de Moura Carvalho. (Org.). Cultura, Percepção e Ambiente: Diálogos com Tim Ingold. São Paulo: Terceiro Nome, 2012.__ Números e narrativas. Debates do NER, v. 2, n. 24, 2013 a $\mathrm{O}$ que os homens e as mulheres podem fazer com números que fazem coisas. In: TEIXEIRA, Faustino; MENEZES, Renata (Orgs.). Religiões em movimento: o censo de 2010. Petrópolis: Vozes, 2013b._ Santidade e sinceridade na formação da pessoa cristã. Religião \& Sociedade, vol.34, n.1, pp. 173-192, 2014.

MAFRA, Clara, SWATOWISKI, Claudia. O balão e a catedral - trabalho, lazer e religião na paisagem carioca. Revista Anthropológicas, v. 12, p. 141-167, 2008. Mudanças do religioso em uma metrópole em mudança. In: Sandra de Sá Carneiro. (Org.). Cidade: Olhares e Trajetórias. Rio de Janeiro: Garamont, 2009.

MAFRA, Clara, SWATOWISKI, Claudia, SAMPAIO, Camila. Edir Macedo’s Pastoral Project.

ROCHA, Cristina, VASQUEZ, Manuel. Religion Brazilian Diasporas. New York: Brill, 2013.

VELHO, Otávio (org). Circuitos Infinitos. São Paulo. CNPq/Pronex/Attar Editorial. 2003. 